\title{
Sistematização de Algumas Ocorrências de Recursos Educativos DigitAIS PARA O ENSINO DA QUÍMICA
}

\author{
Carla Morais e João Paiva*
}

\begin{abstract}
S 作 educativos digitais disponíveis na Web - em particular simulações, animações e jogos educativos - potencialmente interessantes para o ensino da química no ensino básico e secundário.
\end{abstract}

\section{INTRODUÇÃO}

Os recursos educativos digitais (RED) resultantes da nossa pesquisa estão indicados nas tabelas que a seguir se apresentam nas quais, entre outras informações, se indica o(s) ano(s) de escolaridade no qual cada RED poderá ser integrado (tendo como referência o Currículo Nacional), a respetiva tipologia do RED, o idioma no qual se encontra, bem como a indicação sobre a existência (ou não) de restrições impostas pelos seus autores para a utilização e distribuição do mesmo.

Isto é, se os RED podem ser usados e distribuídos sem qualquer limitação nem indicação do autor (Free); se podem ser usados e distribuídos desde que sejam mantidos os créditos dos autores (Autor-utilização/distribuição livre), se, por sua vez, os recursos não podem ser distribuídos e a sua utilização está limitada ao website onde o próprio recurso se encontra alojado, como por exemplo acontece em algumas versões demo (Autor-utilização/ distribuição limitada).

Faz-se também um exercício de apreciação dos RED, recorrendo-se à atribuição simbólica de estrelas, baseada em juízos de valor sobre as potenciais mais-valias da sua utilização para o ensino e para a aprendizagem da química. Com o intuito de facilitar a leitura da informação que se pretendeu

* Faculdade de Ciências da Universidade do Porto Unidade de Ensino das Ciências, Departamento de Química e Bioquímica

Centro de Investigação em Química

E-mail: jcpaiva@fc.up.pt sistematizar, recorreu-se a algumas abreviaturas que julgamos aligeirarem a densidade do texto apresentado (Tabela 1).

RED SOBRE ESTADOS FÍSICOS DA MATÉRIA E PONTO DE FUSÃO E PONTO DE EBULIÇÃO

Numa primeira fase, começou-se por realizar uma pesquisa na internet usando as seguintes palavras-chave: destilação fracionada, estados físicos da matéria, ponto de fusão e ponto de ebulição. Além de acompanhadas pelos complementos: simulação; digital; interação e software educativo, as palavras-chave foram convenientemente traduzidas para língua inglesa e espanhola de modo a ampliar o raio de ação da nossa pesquisa.

Na Tabela 2 apresenta-se uma sistematização das ocorrências relacionadas com as palavras-chave indicadas.

Verificou-se que a maior parte dos RED encontrados estão disponíveis em língua inglesa e apresentam um baixo índice de interatividade com 0 utilizador tratando-se, na sua maioria, de animações computacionais que têm como principal propósito enfatizar determinadas características superficiais macroscópicas ou microscópicas não incluindo, necessariamente, valores teóricos ou empíricos de propriedades físicas e/ou químicas.

Alguns dos RED apresentados na Tabela 2 só se encontram disponíveis na sua versão demo (uma versão mais limitada), não sendo possível uma exploração mais completa dos mesmos.
RED SOBRE PRESSÃO DE UM GÁS, MOVIMENTOS CORPUSCULARES E CONDUTIVIDADE ELÉTRICA

Numa segunda fase da nossa pesquisa, lançou-se mão das seguintes palavras-chave: pressão de um gás, iões, movimentos corpusculares e condutividade elétrica, relacionadas com temáticas abordadas ao nível do $8 .^{\circ}$ ano de escolaridade. $\mathrm{Na} \mathrm{Ta}$ bela 3, apresentam-se os principais RED encontrados na senda da pesquisa realizada.

Relacionados com a temática das propriedades dos gases encontraram-se cinco simulações computacionais que permitem a manipulação de diferentes variáveis, sendo de sublinhar que duas delas se encontram em língua portuguesa - um, mais recente (data de 2011), resultou da tradução de uma versão originalmente desenvolvida em língua inglesa pela Universidade do Colorado.

Para a temática dos iões e da respetiva condutividade elétrica de soluções iónicas, foram escassos os recursos interativos encontrados.

Apenas se encontraram dois registos: um jogo sobre nomenclatura e fórmulas de compostos iónicos, em língua portuguesa, e uma simulação sobre a condutividade elétrica e a sua relação com a presença de iões em solução, em língua inglesa.

\section{RED sobre Tabela Periódica E CONFIGURAÇÕES ELETRÓNICAS}

Numa terceira fase da pesquisa realizada, usaram-se como palavras-cha- 
ve: Tabela Periódica e configurações eletrónicas.

Os resultados desta pesquisa apresentam-se na Tabela 4.

Sendo a Tabela Periódica uma importantíssima sistematização feita em Química, muitas foram as ocorrências de RED relacionadas com esta temática.

\section{RED SOBRE OUTRAS TEMÁTICAS} DE QUIIMICA GERAL

Além das pesquisas pautadas por critérios de especificidade temática, realizou-se também uma pesquisa mais genérica, usando como palavras-chave: simulação em química, software educativo em química e recursos interativos em química, da qual resultou um vasto conjunto de RED, que julgamos apresentarem potencial científico e pedagógico para o ensino da Química, se devidamente integrados em contexto educativo.

$\mathrm{Na}$ Tabela 5, apresentam-se alguns exemplos destes recursos.

\section{CONSIDERAÇÕES FINAIS}

A sistematização apresentada reforça a ideia de que a produção de software deve ter em especial atenção a realização de recursos em língua portuguesa, nas áreas e níveis disciplinares mais deficitários e que vão ao encontro dos interesses e motivações específicos dos jovens a quem se destinam. Da mesma forma, continuam a ser cruciais mais investigações sobre a integração pedagógica dos RED em contexto educativo com vista a potenciar, nos alunos, o desenvolvimento das mais diversas competências.

\section{Nota}

Este artigo também está disponível no site da Sociedade Portuguesa de Química (http://www.spq.pt/QUIMICA/ multimedia), onde os leitores poderão aceder diretamente às referências e recursos mencionados.

Tabela 1 - Abreviaturas utilizadas na sistematização de algumas ocorrências de RED

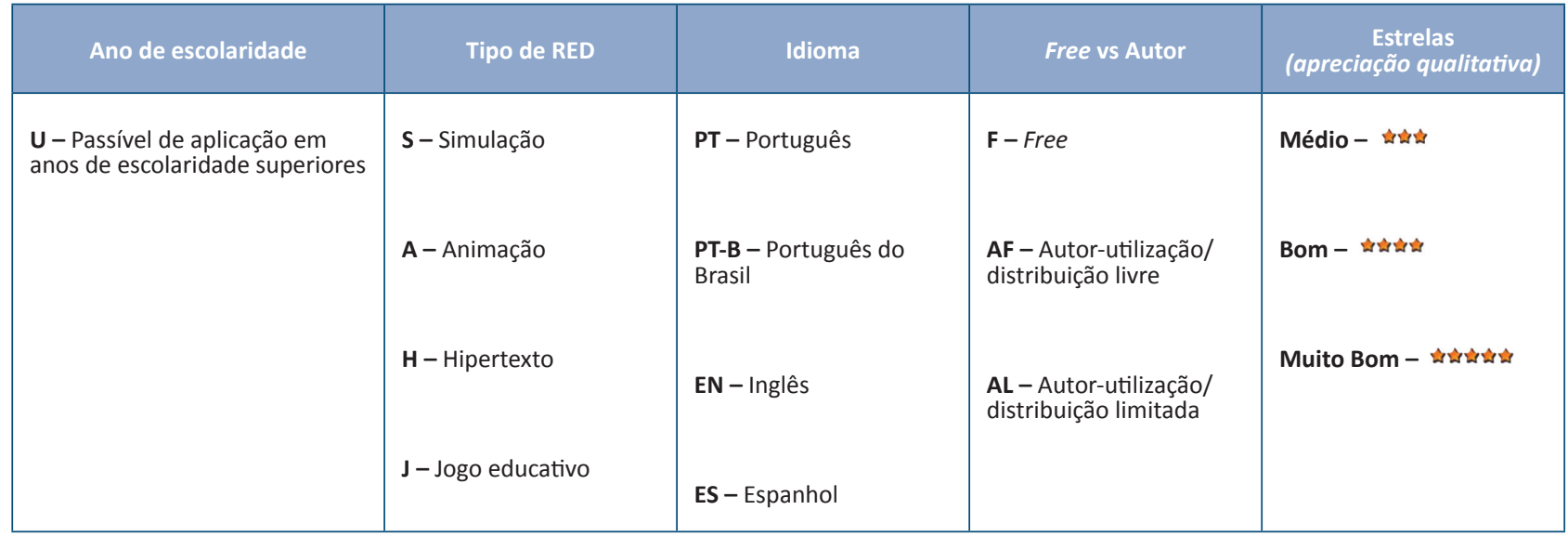

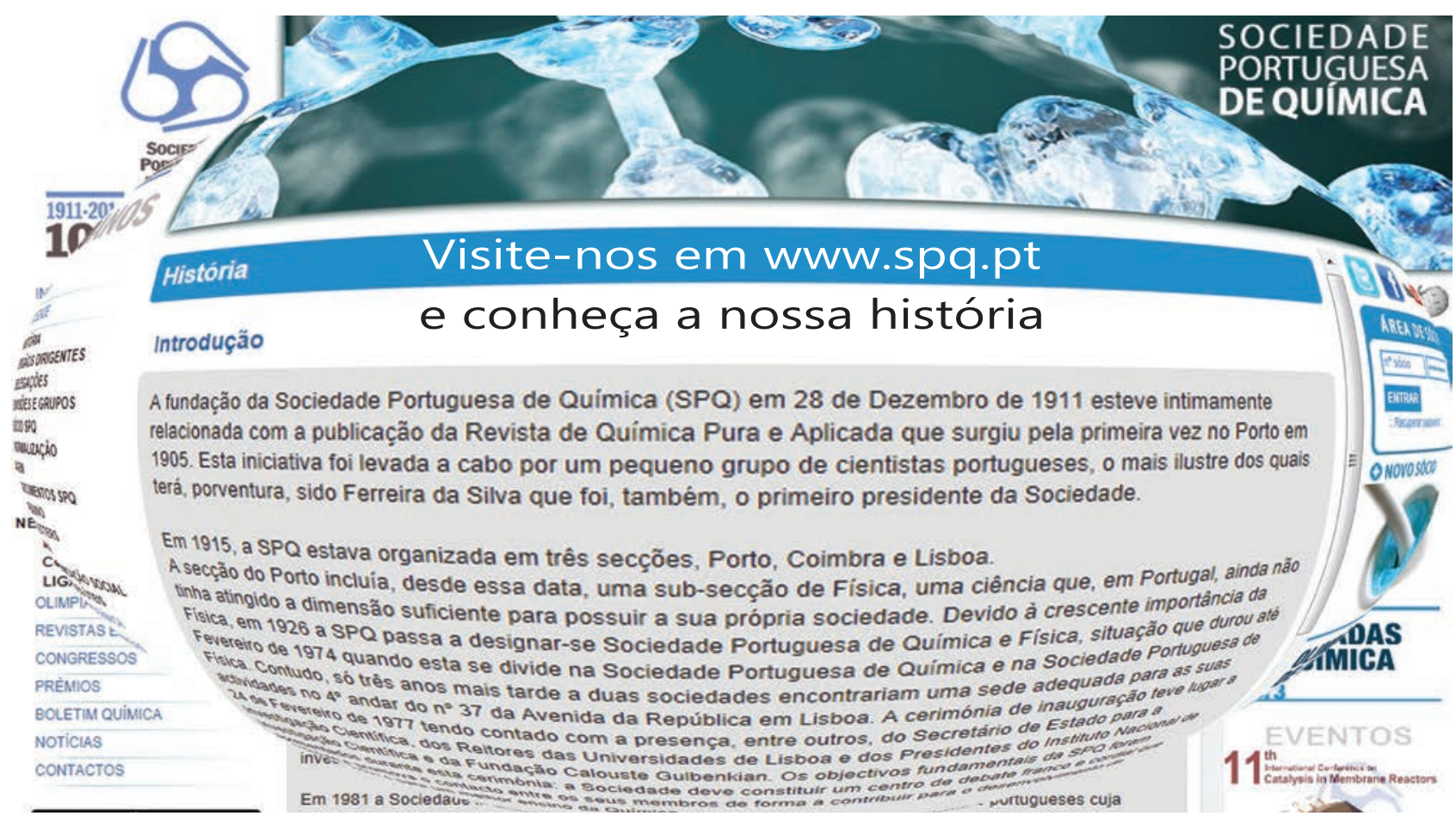




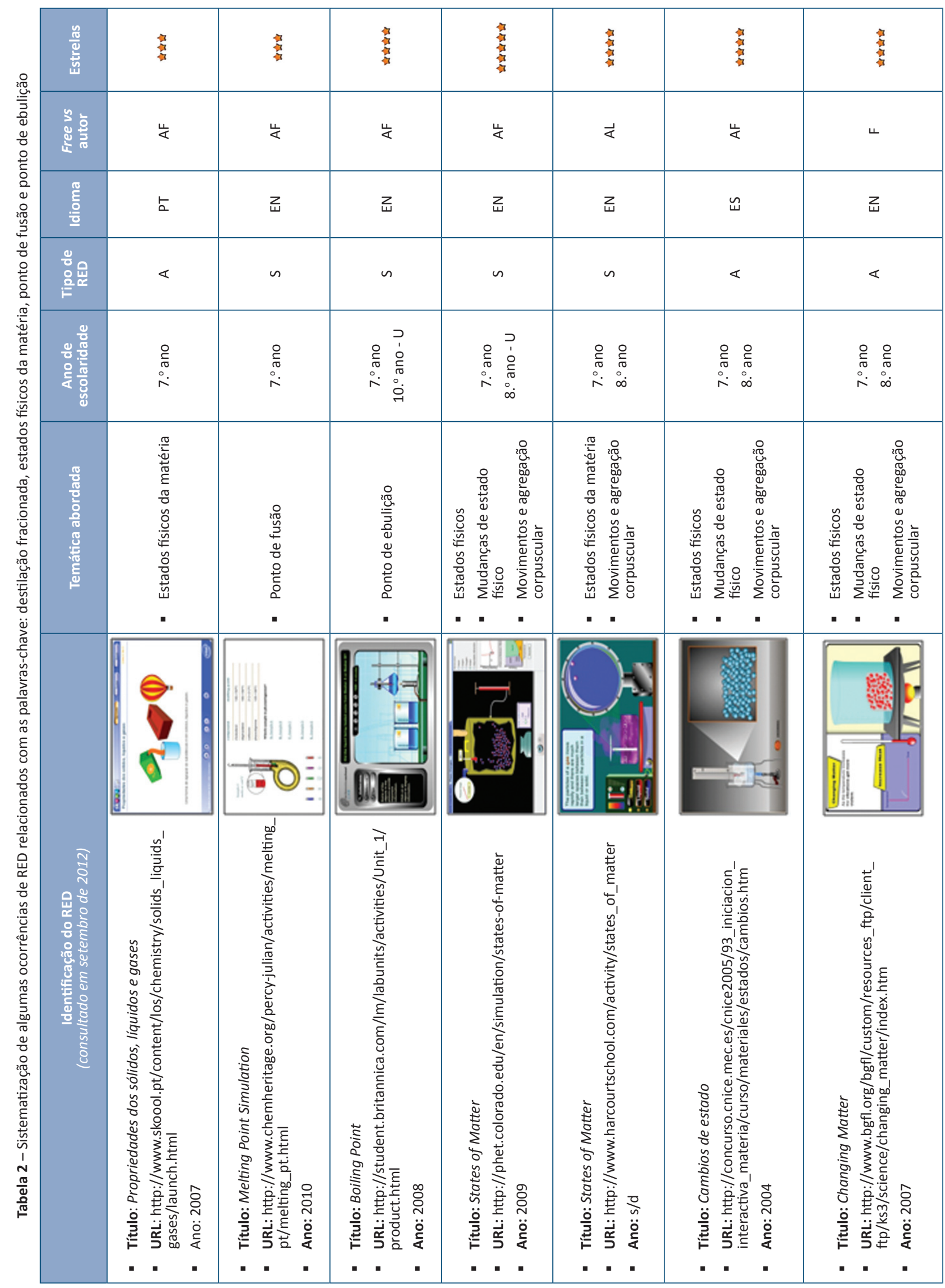




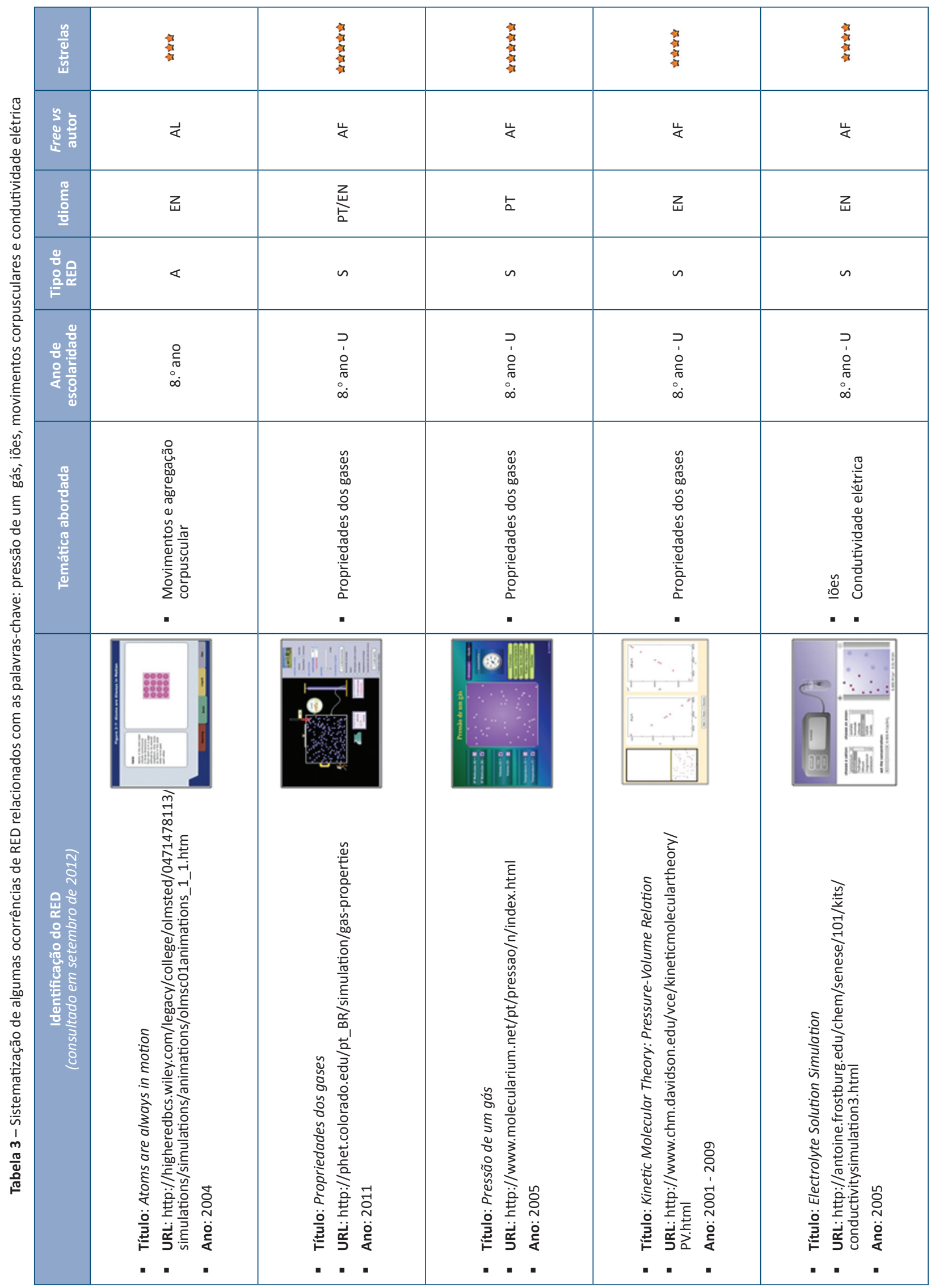




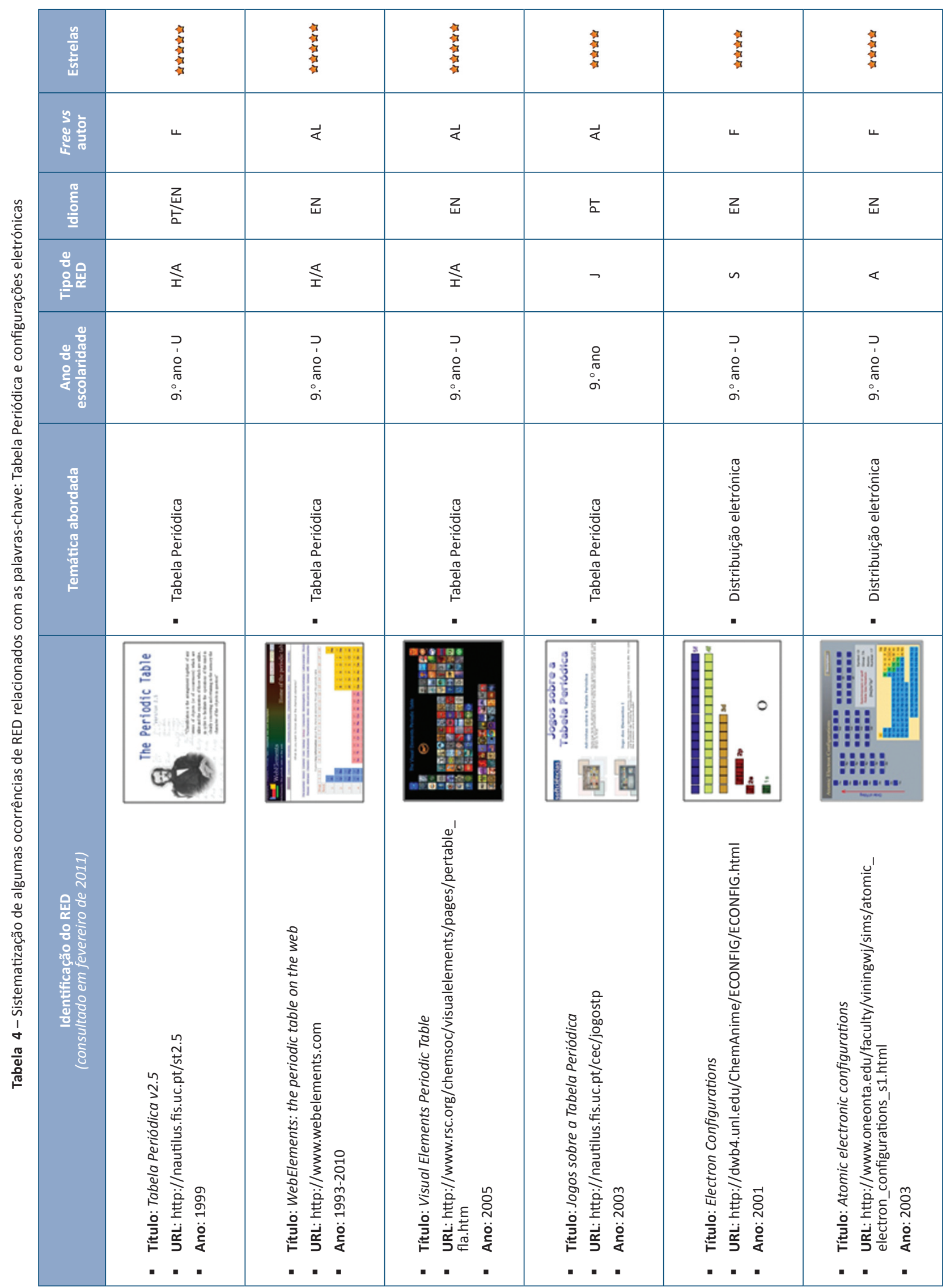




\begin{tabular}{|c|c|c|c|c|c|c|c|}
\hline 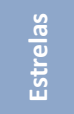 & 离 & 离 & 瓿 & 离 & 离 & 瓿 & 霥 \\
\hline 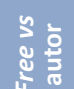 & 峞 & 峞 & 崖 & 峞 & 峞 & $\vec{\varangle}$ & 岩 \\
\hline 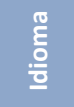 & 占 & $\underset{\text { 点 }}{z}$ & z & $z_{u}$ & zu & z & z \\
\hline $\begin{array}{l}\text { 응요 } \\
\text { 은 }\end{array}$ & $n$ & $n$ & $n$ & $\frac{\mathbb{s}}{n}$ & $n$ & $\backsim$ & $\backsim$ \\
\hline 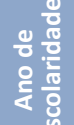 & 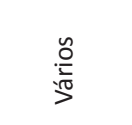 & $\frac{\stackrel{n}{\circ}}{\stackrel{0}{* \pi}}$ & 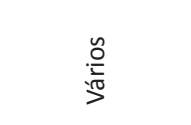 & 总 & 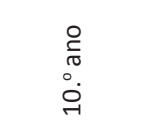 & $\begin{array}{l}\stackrel{\circ}{\circ} \\
\circ \\
\dot{7}\end{array}$ & $\begin{array}{l}\stackrel{\circ}{0} \\
\circ \\
\dot{7}\end{array}$ \\
\hline 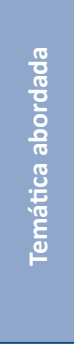 & 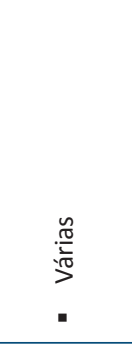 & : & : & 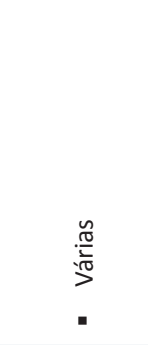 & 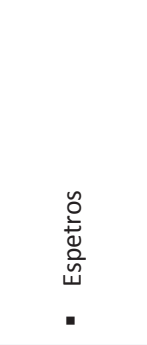 & 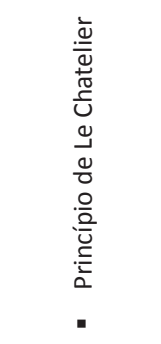 & 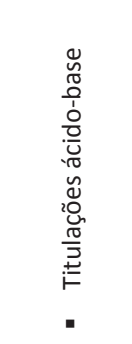 \\
\hline & 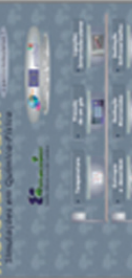 & 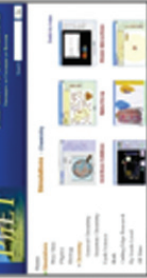 & 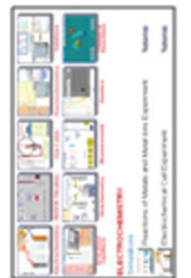 & $\int_{0}^{1}\left|\begin{array}{ll}1 \\
\\
1\end{array}\right|$ & | & 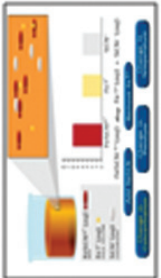 & $\frac{1}{4}$ \\
\hline 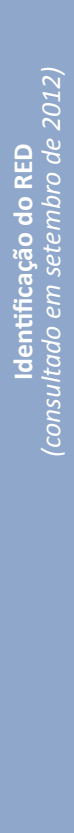 & 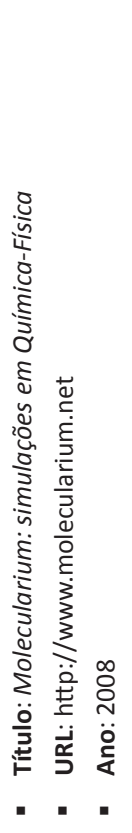 & 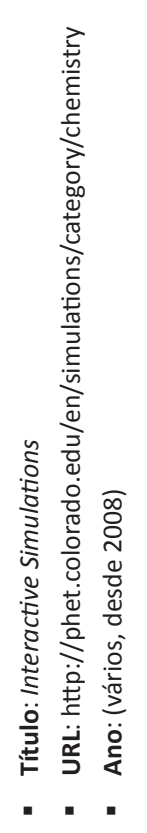 & 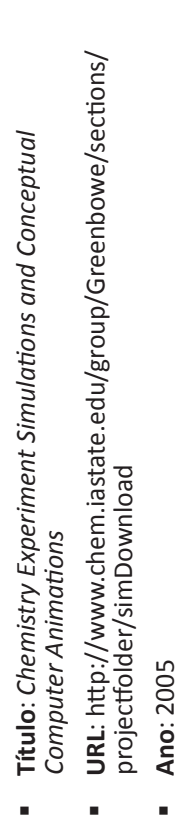 & 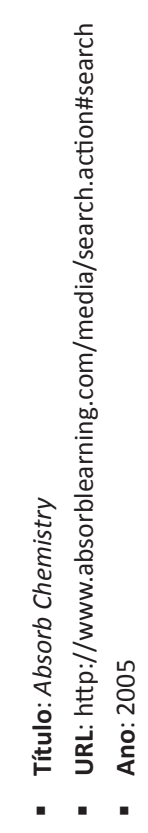 & 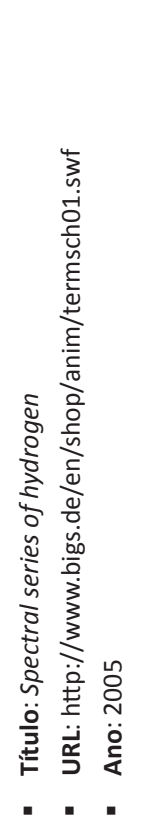 & 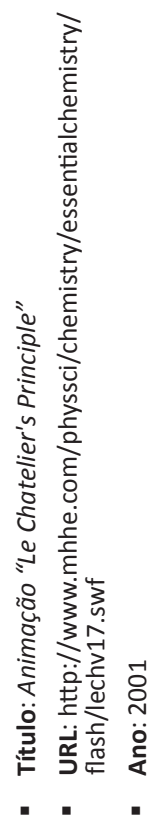 & 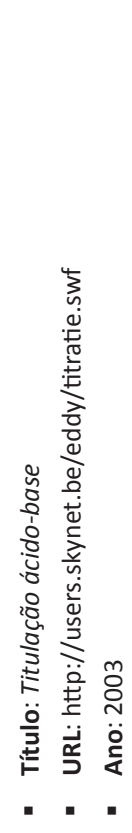 \\
\hline
\end{tabular}

